\title{
Influence of folic acid on birthweight and growth of the erythroblastotic infant
}

\author{
I. Birthweight
}

\section{GILLIAN GANDY AND W. JACOBSON*}

From Strangeways Research Laboratory, Cambridge, and Cambridge Maternity Hospital

SUMMARY The birthweights of 100 infants with erythroblastosis were carefully matched as to sex, gestational age, and parity with the birthweights of 200 control infants born during the same period. At all gestational ages the average birthweight of the affected infants was below that of the controls, the average reduction being $227 \mathrm{~g}$. The more severely affected infants tended to be at a lower centile for birthweight than were the mildly affected ones.

The relationships between maternal serum folate, cord blood serum folate, and centile for birthweight among affected infants were also studied. There was a strong correlation between low maternal serum folate and the incidence of small-for-dates babies among the affected infants. There was also a strong correlation between maternal and cord blood serum folate values. There was a lack of correlation between maternal serum folate and cord blood haemoglobin. It is concluded that infants with erythroblastosis are lighter than controls and that the reason for this may be a shortage of folic acid available for fetal growth.

The study was prompted by posing the question as to whether a deficiency of folic acid might play a role in the anaemia of infants with erythroblastosis. Before birth the fetus affected by Rhesus haemolytic disease shows markedly increased bone marrow activity in response to red cell destruction, with increased numbers of nucleated red cells and reticulocytes in the blood. Some time after birth, however, there appears to be a lack of response in the bone marrow, despite the continuance or development of an anaemia, and it is usually not until after 4-6 weeks of postnatal life that a reticulocyte response occurs, followed by a rise in haemoglobin. Thus a shortage of folic acid might aggravate the anaemia particularly after birth if folate stores are being depleted.

In the early part of the study an undue preponderance of babies who were relatively small for gestational age was noted and further attention was focused on this aspect. The question arises as to what factors might depress the intrauterine growth in these infants. Since folic acid is an essential factor

Received 5 April 1976

*Sir Halley Stewart Research Fellow for cell multiplication in all tissues (i.e. not only in bone marrow), it is possible that a shortage of this compound might lead to a reduction in growth rate. Such a shortage is only likely to occur in the fetus if the mother herself is relatively deficient in folic acid.

This series of three papers explores the possible role of folic acid as an essential growth factor (as distinct from its well recognized function in haemopoiesis). The infants studied all had erythroblastosis, but it should be pointed out that the same principles may equally apply to nonerythroblastotic infants with low folic acid levels. The first paper is concerned with the inter-relationship between birthweight, serum folate (maternal and fetal), and haemoglobin at birth in infants with erythroblastosis.

The second paper describes the correlation between serum folate and the growth of erythroblastotic infants during the first year of life. (It will be shown that when serum folate is low infants tend to grow less well than when serum folate levels are satisfactory.)

The third paper shows, in a pilot study, the beneficial effect of folate supplementation on the rate of growth of 17 erythroblastotic infants. 
Material

Birthweight and erythroblastosis. In order to assess the possible influence of erythroblastosis upon birthweight, the records of 100 infants with this disease, born in the United Cambridge Hospitals during the years 1968-1971, were examined. The gestational age of each infant was calculated in days from the date of the mother's last menstrual period and was then recorded as completed whole weeks of gestation. Only cases in which the date was known with reasonable certainty were included. Each index case was then matched with 2 control cases without erythroblastosis. The controls were selected by taking from the delivery records the next 2 consecutively born infants who matched the index case as to gestational age (completed weeks) and sex. Since all the mothers in the erythroblastotic group were multiparous, this criterion was also applied to the mothers of the control infants, though the parity could not be matched exactly. Infants with major congenital malformations were excluded, as were those born to mothers with diabetes or those who had severe complications of pregnancy. No infant in either group was hydropic or oedematous. The incidence of mild preeclamptic toxaemia was similar in both groups, 2 for the index cases and 5 for the controls. The social class distribution was similar in both groups, but the incidence of smoking among the mothers is unknown.

For each index and control case the following data were transferred to punch cards: maternal age, parity, height, and complications of pregnancy. For each infant the gestational age, expressed as completed weeks, and birthweight was recorded. The centile for weight at birth was derived from the charts of Thomson et al. (1968) after making due allowance for sex, gestational age, and maternal height. For the cases of erythroblastosis the following additional data were entered onto the punch cards: cord blood $\mathrm{Hb}$ and serum bilirubin, together with the number of exchange transfusions and/or subsequent 'top-up' transfusions. Thus 100 infants with erythroblastosis were carefully matched with 200 normal infants, each index case being compared with its 2 controls.

Blood samples. Maternal blood for serum folate determination was obtained on the day of delivery from a total of 69 mothers of infants with erythroblastosis. These samples included 44 from the 100 cases used for the birthweight analysis together with 25 from a subsequent series. Serum folate assays were also performed on the cord blood from 75 infants with erythroblastosis.
Methods

Serum folate determination. Blood was collected either by venepuncture, or from the umbilical cord immediately after delivery. After clotting, the blood was centrifuged and the serum frozen immediately and kept at $-5^{\circ} \mathrm{C}$ until it was assayed either the same afternoon or within one week, strict sterility being preserved throughout. All determinations were done in duplicate by a method that has been in use for over 20 years and has given consistent results with Lactobacillus casei var. rhamnosus (NCIB 6375; ATCC 7469). The assay medium was either Difco's or Becton and Dickinson's; each batch of assay medium was checked for its suitability by determining the 'blank' reading with L. case $i$ without added folic acid.

Every assay was run with its own standards, consisting of 2 'blank' tubes (without added folate), 2 tubes each with $10,40,100$, and $250 \mathrm{pg} / \mathrm{ml}$ folate, from aldehyde-free, nonfluorescing, chromatographically pure folic acid kept in a sterile stock solution of $10 \mu \mathrm{g} / \mathrm{ml}$ at $0-3^{\circ} \mathrm{C}$ where it retains its activity unchanged for 3-4 months. The experimental tubes contained $0.05 \mathrm{ml}$ serum, added under sterile conditions to a total of $5 \mathrm{ml}$ sterile assay medium with $2.5 \mathrm{mg}$ ascorbic acid/ml. Optical density of all tubes was read on a Hilger Absorptiometer before incubation, and these zero-hour values were deducted from all subsequent readings which were taken at approximately 18, 24, 42, 48, and 66 hours.

The density readings of standard and experimental tubes were graphed to ensure that the change in density followed a characteristic pattern and, especially, that the density of the experimental tubes stayed between the curves of the standards, without crossing over them (Fig. 1). This served as a check that the growth pattern of the experimental tubes fell into that of the standards. Thus bacterial growth in each assay tube was monitored, and every assay had its own internal standards. If only one initial and one final reading of each tube had been taken, the end-result might have been less reliable, as experimental tubes could grow at a rate quite different from the standards and thus cross standard lines.

The term folic acid or folate is used throughout this paper to mean 'total folates', i.e. to include all derivatives of folic and tetrahydrofolic acids as measured by $L$. casei.

\section{Results}

Influence of erythroblastosis on birthweight. By definition the 100 index cases with erythroblastosis and their 200 controls (normal infants) were matched 


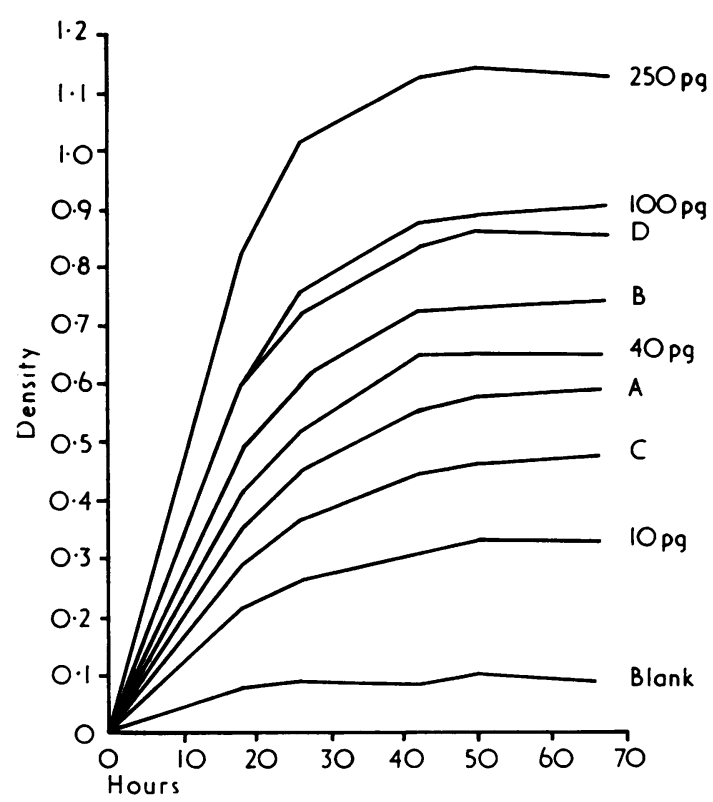

Fig. 1 Growth of $\mathrm{L}$. casei in 'standard' tubes containing $250,100,40$, and 10 pg folic acid/ml medium, and growth in four sets of experimental tubes containing $0.01 \mathrm{ml}$ serum $/ \mathrm{ml}$ medium from infants $A, B, C, D$.

Note: the curves in the experimental tubes do not cross over those of the standard tubes.

as to sex and gestational age. In each group there were $53 \%$ males and $47 \%$ females. Gestational age ranged from 34 to 41 weeks (mean 37.9, median 38). Maternal height was comparable in the two groups. The mean birthweights for both groups at each week of gestational age from 34 to 41 weeks are shown in Fig. 2. The erythroblastotic infants were consistently lighter than the controls. In order to evaluate this difference statistically, each index case and its two controls were considered separately; this was done by subtracting the birthweight of each index case from the average weight of its 2 controls. The 'reduction in birthweight' ranged from $+1675 \mathrm{~g}$ (lighter) to $-1296 \mathrm{~g}$ (heavier). The hypothesis that there was no difference was tested by Student's ' $t$ ' test and was rejected $(t=4 \cdot 543, P<0 \cdot 001)$. Thus the controls were significantly heavier than the erythroblastotic cases, the average difference being $227 \mathrm{~g} \pm 50 \mathrm{SE}$. There were no significant relationships between 'reduction in birthweight' and cord blood $\mathrm{Hb}$ or cord serum bilirubin.

In the distribution of weight centiles of the index and control cases (Fig. 3), the centiles of the controls are more uniformly spread than are those of the erythroblastotic infants, the latter group having

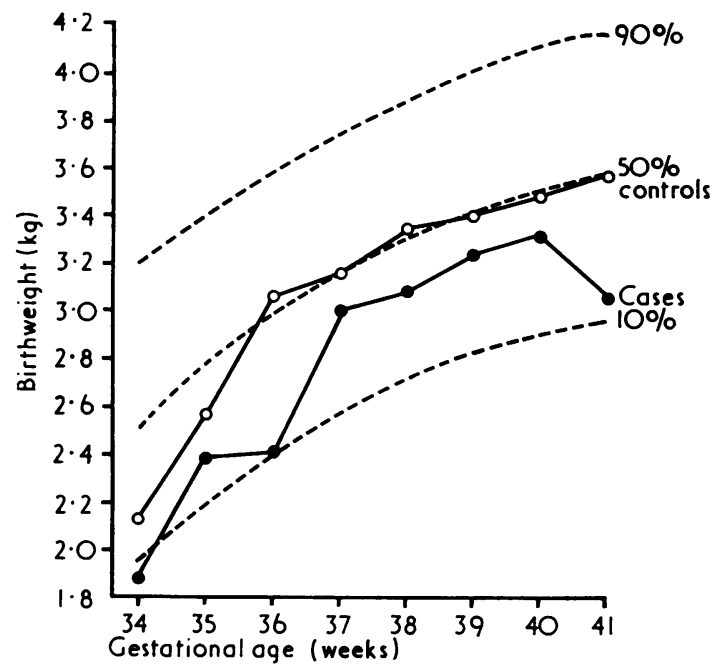

Fig. 2 Correlation of gestational ages and birthweights based on 200 'normal' controls matched as to prematurity, sex, and parity with 100 infants with erythroblastosis fetalis. Note: at every gestational age the erythroblastotic infants are lighter than the controls.
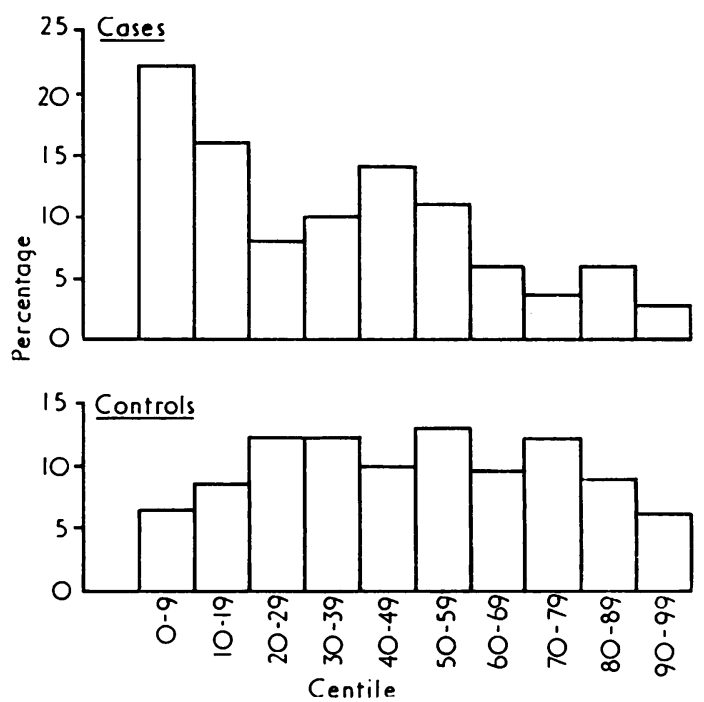

Fig. 3 Distribution of centiles of birthweights of 100 infants with erythroblastosis fetalis ('cases') and 200 normal infants ('controls') matched as to prematurity, sex, and parity.

a preponderance of babies below the 20th centile. The mean centile for the controls was 51 , whereas that for the index cases was 34 , a highly significant difference $(\mathrm{t}=3 \cdot 453, \mathrm{P}<0.001)$. 
Table 1 Cumulative percentages of birthweights in 100 infants with erythroblastosis, mild or severe, and in 200 controls

\begin{tabular}{|c|c|c|c|c|c|c|}
\hline Centiles & $0-10$ & $0-25$ & $0-50$ & $0-75$ & $0-90$ & Totals \\
\hline $\begin{array}{l}\text { Controls } \\
\text { Mildly affected group } \\
\text { Severely affected group }\end{array}$ & $\begin{array}{l}10 \\
20 \\
38\end{array}$ & $\begin{array}{l}29 \\
33 \\
53\end{array}$ & $\begin{array}{l}52 \\
65 \\
83\end{array}$ & $\begin{array}{l}85 \\
90 \\
92\end{array}$ & $\begin{array}{r}97 \\
100 \\
100\end{array}$ & $\begin{array}{r}200 \\
40 \\
60\end{array}$ \\
\hline
\end{tabular}

Note: The $\mathbf{2 0 0}$ control cases have a normal distribution. The $\mathbf{4 0}$ mild cases have a slight preponderance of lower weights. This is more marked in the 60 severe cases, one-half being below the 25 th centile.

In order to consider whether the degree of severity of erythroblastosis had an effect on birthweight, the infants were subdivided into 2 groups according to the severity of the disease. Mildly affected infants (total number of 40) had a positive Coombs's test in cord blood, but needed neither an exchange nor a subsequent 'top-up' transfusion. The mean cord $\mathrm{Hb}$ was $16.9 \mathrm{~g} / \mathrm{dl}$ and serum bilirubin $2.5 \mathrm{mg} / 100$ $\mathrm{ml}(43 \mu \mathrm{mol} / \mathrm{l})$. Severely affected infants (total number 60) required either one or more exchanges (54 infants), or subsequent 'top-up' transfusions (6) or both (10). The mean cord $\mathrm{Hb}$ was $11.6 \mathrm{~g} / \mathrm{dl}$ and cord serum bilirubin $4.6 \mathrm{mg} / 100 \mathrm{ml}(79 \mu \mathrm{mol} / \mathrm{l})$.

Table 1 shows that the birthweights of more than half the severely affected infants were at or below the 25 th centile and $80 \%$ were at or below the 50 th centile. Among the mildly affected infants about one-third were at or below the 25 th centile and $65 \%$ were below the 50th centile. The control infants showed a fairly normal distribution. Thus severely affected infants had a lower birthweight than mildly affected ones, and both were lighter than control infants.

Serum folate and centiles for weight at birth. In order to test the hypothesis that intrauterine growth towards the end of fetal life might be adversely affected by low maternal folate stores, the following analysis was performed (Table 2). Maternal serum

Table 2 Maternal serum folate and birthweight centiles in 64 infants with erythroblastosis

\begin{tabular}{llll}
\hline $\begin{array}{l}\text { Birthweight } \\
\text { centiles }\end{array}$ & \multicolumn{2}{l}{ Maternal serum } \\
$>8$ & $\leqslant 5$ & Totate $(\mu \mathrm{g} / \mathrm{l})$ & \\
\hline$>10$ & $25(92 \cdot 6 \%)$ & $22(59 \cdot 5 \%)$ & 47 \\
$\leqslant 10$ & $2(7 \cdot 4 \%)$ & $15(40 \cdot 5 \%)$ & 17 \\
Total & 27 & 37 & $64^{*}$ \\
\hline
\end{tabular}

*The 5 samples with borderline values of 5 $1-7 \cdot 9 \mu \mathrm{g} / \mathrm{l}$ are not included.

folate values of 69 mothers were classified according to whether they were (a) $\geqslant 8 \mu \mathrm{g} / 1$ (27 samples), (b) $\leqslant 5 \mu \mathrm{g} / 1$ (37 samples), (c) 5 1-7.9 $\mu \mathrm{g} / 1$ (5 samples, i.e. borderline values). The corresponding infants' birthweights (expressed as centiles) were classified according to whether they were above the 10th centile or at/below the 10th centile. Table 2 shows that when the maternal serum folate was $\geqslant 8 \mu \mathrm{g} / \mathrm{l}$, over $90 \%$ of the infants had a centile above 10 , i.e. the expected distribution. In contrast, when the maternal serum folate was $\leqslant 5 \mu \mathrm{g} / 1$, over $40 \%$ of the infants were at or below the 10th centile, i.e. 4 times the expected frequency. Thus there was a correlation between low maternal serum folate at delivery and low birthweight centile $\left(x^{2}=7 \cdot 2\right.$, $0.01>P>0.005$ ).

The relationship between cord blood serum folate and birthweight centile was not so clear cut. Table 3 shows that $82 \%$ of infants with a serum folate of

Table 3 Cord blood serum folate and birthweight centiles in 70 infants with erythroblastosis

\begin{tabular}{llll}
\hline $\begin{array}{l}\text { Birthweight } \\
\text { centiles }\end{array}$ & \multicolumn{2}{c}{$\begin{array}{c}\text { Cord blood serum folate }(\mu \mathrm{g} / \mathrm{l}) \\
\geqslant 8\end{array}$} & Total \\
\hline$>10$ & $46(82 \%)$ & $8(57 \%)$ & 54 \\
$\leqslant 10$ & $10(18 \%)$ & $6(43 \%)$ & 16 \\
Total & 56 & 14 & $70^{*}$ \\
\hline
\end{tabular}

*The 5 samples with borderline values of $5 \cdot 1-7 \cdot 9 \mu \mathrm{g} / 1$ are not included.

$\geqslant 8 \mu \mathrm{g} / \mathrm{l}$ at birth were above the 10th centile for weight. On the other hand, when the serum folate was less than $5 \mu \mathrm{g} / 1$ only $57 \%$ of the infants were above the 10th centile. These results, though suggestive, are not significant $\left(\chi^{2}=2 \cdot 7,0.025>\mathrm{P}>\right.$ 0.0125 ).

Although there was no direct linear correlation between maternal and cord blood serum folate, Table 4 shows that when the maternal folate was $\geqslant 8 \mu \mathrm{g} / \mathrm{l}$ none of the infants had values less than $5 \mu \mathrm{g} / \mathrm{l}$. In contrast, when the maternal folate was

Table 4 Maternal and cord blood serum folate in 55 infants with erythroblastosis

\begin{tabular}{llll}
\hline $\begin{array}{l}\text { Cord blood } \\
\text { serum folate } \\
(\mu g / l)\end{array}$ & \multicolumn{2}{l}{$\begin{array}{l}\text { Maternal serum folate }(\mu g / l) \\
\leqslant 8\end{array}$} & Total \\
\hline$\geqslant 8$ & $24(100 \%)$ & $20(64 \cdot 5 \%)$ & \\
$\leqslant 5$ & 0 & $11(35 \cdot 5 \%)$ & 11 \\
Total & 24 & 31 & 55 \\
\hline
\end{tabular}


$\leqslant 5 \mu \mathrm{g} / 1$ about one-third of the corresponding infants were also deficient.

Thus a relatively high maternal serum folate was always associated with a satisfactory cord blood level and the corresponding infants were usually above the 10th centile for weight. On the other hand, when the maternal folate was suboptimal, about one-third of the infants were also deficient in folate and $40 \%$ of them were at or below the 10th centile. In contrast to the positive correlation between maternal folate and birthweight centile, no relationship could be established between cord blood $\mathrm{Hb}$ and either maternal or fetal serum folate values.

\section{Discussion}

There has been conflicting evidence as to whether the birthweight of infants with erythroblastosis is lower than that of normal infants. Naeye (1967), Kitchen (1970), and Vidyasagar (1971) reported no difference; Karnicki (1968) found erythroblastotic infants to be heavier than normal, but her figures for normal standards were unusually low (see Binks et al., 1973). Lind and Hytten (1969) found infants with erythroblastosis to be lighter than normal, though no figures were given. Binks et al. (1973) have shown clearly that not only is the birthweight of erythroblastotic infants decreased, but that the more severe the disease the lower the birthweight for a given gestational age. Our study has shown conclusively that infants with erythroblastosis have a birthweight slightly lower than that of carefully matched controls. This holds true for all gestational ages, the average difference being $227 \mathrm{~g}$. Furthermore, the more severely affected infants, as judged by the need for exchange or 'top-up' transfusions, tend to have a lower centile for birthweight than do mildly affected infants. Richings (1973) reported on the development of 18 erythroblastotic infants who had received intrauterine transfusions. Though the author states that their birthweights fell within the normal range, her Table 1 shows that 9 infants were at the 25th centile or less and 15 of the 18 infants were at or below the 50th centile. Thus, even her small series shows the preponderance of lower birthweights as found by us.

No satisfactory explanation for this impaired intrauterine growth rate has yet been suggested, and it was therefore of great interest to find that there was a correlation between low maternal serum folate and a low centile for birthweight. Mothers with serum folate below $5 \mu \mathrm{g} / \mathrm{l}$ gave birth to 4 times as many infants with a weight centile of 10 or less than would be expected, whereas mothers with levels over 8 $\mu \mathrm{g} / \mathrm{l}$ delivered the expected number of infants at or below the 10th centile. The mothers were all supposedly on folic acid supplements throughout most of their pregnancy, but it seems more than likely that some of them were not actually taking it; this was not due to low socioeconomic status. Further support for this comes from the observation that about one-third of the infants born to folatedeficient mothers also had a low cord blood serum folate level. In contrast, none of the infants born to mothers with satisfactory folate levels were themselves folate deficient at birth. The fact that there was not a significant correlation between low cord blood serum folate and low birthweight centile does not detract from the argument, because it is generally agreed that cord blood serum folate is usually considerably higher than that in the maternal serum. This is probably due to the trophoblast actively transporting folate into the fetal plasma against a concentration gradient (Strelling, 1976). Folate concentration in the cord blood is therefore not a true reflection of folate stores in the fetus. A more accurate reflection of the folate status would probably be obtained by determing serum folate after the first days of life, when the value has dropped to a more basic level.

Whiteside et al. (1968) studied the effect of maternal serum folate, iron, and vitamin $B_{12}$ on the infant's birthweight and calculated a regression equation:

$$
y=2138+538 \cdot 2 x_{1}+7 \cdot 788 x_{2}+1 \cdot 631 x_{3}
$$

where $y=$ the infant's birthweight $(g), x_{1}=\log$ maternal serum folate $(\mu \mathrm{g} / \mathrm{l}), \mathrm{x}_{2}=$ maternal serum iron $(\mathrm{mg} / \mathrm{dl})$, and $\mathrm{x}_{3}=$ maternal serum $B_{12}(\mathrm{ng} / \mathrm{l})$. From this formula it can be seen that the influence of maternal serum folate on the infant's birthweight is not inconsiderable. Lillie (1962) found a smaller number of babies with low birthweight when the mothers had been supplemented with $5 \mathrm{mg} / \mathrm{d}$ folic acid, but $0.5 \mathrm{mg} / \mathrm{d}$ had no effect on the birthweight (Willoughby, 1967).

Evidence about the relationship between megaloblastic anaemia of pregnancy and the infant's birthweight has been conflicting. Gatenby and Lillie (1960) reported that $12.5 \%$ of infants born to mothers with megaloblastic anaemia weighed less than $2 \cdot 5 \mathrm{~kg}$ (i.e. a centile of $<3$ at term). This result agrees with our figure of 4 times the expected frequency of small-for-dates babies born to mothers with a serum folate level $\leqslant 5 \mu \mathrm{g} / \mathrm{l}$. On the other hand, Chanarin et al. (1968) and Varadi et al. (1966) reported that megaloblastic anaemia of pregnancy had no adverse effect on the infant's birthweight. These results could perhaps be explained, if the diagnosis of megaloblastic anaemia (and folate deficiency) had been made before the last month of 
pregnancy and therefore presumably the mothers had been treated for some time before they actually delivered.

There was no correlation in this series between low maternal serum folate and low cord $\mathrm{Hb}$, nor did any of the infants have a macrocytic anaemia. This is not to deny that folic acid has a profound influence upon erythropoiesis, but it emphasizes the principle that folate deficiency in the rapidly growing fetus may become manifest by a diminished growth rate before the development of a macrocytic anaemia. This aspect of the argument will be further developed in the following paper.

Although all our data concern infants with haemolytic disease, it is possible that the relationship between low maternal serum folate, towards the end of pregnancy, and 'small-for-dates' infants may also hold true for conditions other than erythroblastosis.

The authors gratefully acknowledge the support given by the Trustees of the Sir Halley Stewart Trust throughout this investigation. Our thanks are due to the nursing staff of the Cambridge Maternity Hospital for unfailing co-operation; to Dr. D. Gairdner, then senior paediatric consultant, for his contribution in initiating the investigation; to Miss J. M. Nixon and Mr. N. F. Nelson of the Medical Statistics Section, Department of Human Ecology, Cambridge University, for statistical assistance; to Mrs. Phyllis Parkinson for her work in the assay of folate; to Mrs. Jennifer Routledge for help in preparing data for publication; and to the secretarial staff of the Strangeways Research Laboratory.

Part of the expenses have been defrayed by the Medical Research Council.

\section{References}

Binks, A. S., Lind, T., and McNay, R. A. (1973). Effect of rhesus haemolytic disease upon the birthweight. Journal of
Obstetrics amd Gynaecology of the British Commonwealth, 80, 301-304.

Chanarin, I., Rothman, D., Ward, A., and Perry, J. (1968). Folate status and requirement in pregnancy. British Medical Journal, 2, 390-394.

Gatenby, P. B. B., and Lillie, E. W. (1960). Clinical analysis of 100 cases of severe megaloblastic anaemia of pregnancy. British Medical Journal, 2, 1111-1114.

Karnicki, J. (1968). Results and hazards of prenatal transfusion. Journal of Obstetrics and Gynaecology of the British Commonwealth, 75, 1209-1213.

Kitchen, W. H. (1970). Birthweight of infants with rhesus incompatibility. Australian and New Zealand Journal of Obstetrics and Gynaecology, 10, 30-32.

Lillie, E. W. (1962). Obstetrical aspects of megaloblastic anaemia of pregnancy. Journal of Obstetrics and Gynaecology of the British Commonwealth, 69, 736-738.

Lind, T., and Hytten, F. E. (1969). Relation between birthweight and rupture-delivery interval. Lancet, 1, 917-918.

Naeye, R. L. (1967). New observations in erythroblastosis fetalis. Journal of the American Medical Association, 200, 281-286.

Richings, J. (1973). Later progress of infants who received transfusions in utero for severe rhesus haemolytic disease. Lancet, 1, 1220-1222.

Strelling, M. K. (1976). Transfer of folate to the fetus. Developmental Medicine and Child Neurology, 18, 533-535,

Thomson, A. M., Billewicz, W. Z., and Hytten, F. E. (1968). The assessment of fetal growth. Journal of Obstetrics and Gynaecology of the British Commonwealth, 75, 903-916.

Varadi, S., Abbott, D., and Elwis, A. (1966). Correlation of peripheral white cell and bone marrow changes with folate levels in pregnancy and their clinical significance. Journal of Clinical Pathology, 19, 33-36.

Vidyasagar, D. (1971). Birthweight in haemolytic disease of the newborn. Archives of Disease in Childhood, 46, 113-115.

Whiteside, M. G., Ungar, B., and Cowling, D. C. (1968). Iron, folic acid and vitamin $B_{12}$ levels in normal pregnancy and their influence on birthweight and the duration of pregnancy. Medical Journal of Australia, 1, 338-342.

Willoughby, M. L. N. (1967). An investigation of folic acid requirements in pregnancy. II. British Journal of Haemato$\log y, 13,503-509$.

Correspondence to Dr. W. Jacobson, Strangeways Research Laboratory, Cambridge CB1 4RN. 